\title{
Hypersexuality following subthalamic nucleus stimulation for Parkinson's disease
}

\author{
Paresh Doshi, Pranshu Bhargava \\ Department of Stereotactic and Functional Neurosurgery, Jaslok Hospital and Research Centre, Mumbai, India
}

\begin{abstract}
Subthalamic nucleus (STN) stimulation is an established surgical treatment for Parkinson's disease (PD). Though the motor benefits of STN stimulation are well understood, its cognitive and behavioral effects are still not fully understood. Manic psychosis, hypersexuality, pathological gambling and mood swings are associated with advanced PD. There have been reports to suggest improvement or worsening in these symptoms following STN deep brain stimulation (DBS). We report two cases as the sole behavioral side-effects of STN stimulation despite good clinical improvement on long-term follow-up. These patients and literature review suggests the complex role of STN stimulation in motor and behavioral control.
\end{abstract}

Key words: Behavioral side-effects, DBS, hypersexuality, Parkinson's disease, STN stimulation.

\section{Introduction}

High-frequency stimulation (HFS) of the subthalamic nucleus (STN) is known to improve motor symptoms of Parkinson's disease (PD) and reduce dopminergic intake. ${ }^{[1]}$ However, the role of STN stimulation in modifying behavior and cognition in a given patient is poorly understood. Various reports have described a wideranging impact of STN stimulation from alleviation of depression ${ }^{[2]}$ to precipitating depression; ${ }^{[3,4]}$ weight gain; induction of manic behavior ${ }^{[5]}$ to relieving manic behavior and other cognitive changes. ${ }^{[6]}$ There has been mention of isolated transient hypersexual behavior or sexual "wellbeing" in some reports..$^{[7,8]}$

We have performed 128 STN stimulations, including 17 patients over the age of 70 years. The selection criteria included PD for more than five years, good response to Levodopa challenge, motor fluctuations and no evidence of major cognitive or psychiatric illnesses. ${ }^{[2]}$ We report two cases who developed hypersexual behavior, despite remarkable motor improvement, without any associated features of hypomania or mania, following STN stimulation

\section{Case Report}

\section{Patient 1}

A 70-year-old gentleman suffering form advanced PD [Table 1], motor fluctuations and dyskinesias underwent bilateral STN stimulation. For two years prior to surgery he was on Zolpidem $10 \mathrm{mg} /$ day, Alprazolam $0.5 \mathrm{mg} /$ day and Fluoxetine $20 \mathrm{mg} /$ day for depression and hallucinations. These were effective in controlling his depression and hallucinations. Our neurologist interpreted these symptoms as manifestations of advanced PD. His Mini Mental State Examination (MMSE) was within normal limits. Postoperatively, he had significant improvement in his PD and reduction in medication [Table 1]. His psychiatric medicines were reduced to $10 \mathrm{mg} /$ day of Zolpidem which was stopped after some time. His stimulation parameters are mentioned in Table 2.

At the one month follow-up visit his wife mentioned that he had become hypersexual. He would insist on sexual gratification every night and would become very aggressive if denied. Once satisfied he would return back to his normal self. The patient realized that though this was exhausting for him, he could not control his urge. In this case, the behavior was unlike that of a normal mature gentleman from a conservative family. As the present contact points were very effective in alleviating all his PD symptoms he and his family were not willing to try any other combinations. During this time he also took to writing his autobiography. His hypersexual behavior continued for almost four years after surgery after which it abruptly stopped without any intervention. However, his wife attributes this change to his recent interaction with a religious "guru". 


\begin{tabular}{|c|c|c|c|c|c|c|c|c|}
\hline \multicolumn{9}{|c|}{ Table 1: Clinical profile of both the patients before and after surgery } \\
\hline \multirow[t]{3}{*}{ Patient } & \multicolumn{5}{|c|}{ Preoperative } & \multicolumn{3}{|c|}{ Postoperative } \\
\hline & \multicolumn{2}{|c|}{ UPDRS OFF $^{*}$} & \multicolumn{2}{|c|}{ UPDRS ON ${ }^{\dagger}$} & \multirow[t]{2}{*}{ LEDD $\ddagger$} & \multicolumn{2}{|c|}{ UPDRS OFF§ } & \multirow{2}{*}{ LEDD } \\
\hline & Total & Motor & Total & Motor & & Total & Motor & \\
\hline 1 & 109 & 72 & 46 & 27 & 1100 & 62 & 24 & 450 \\
\hline 2 & 114 & 77 & 64 & 45 & 1200 & 63 & 34 & 700 \\
\hline \multicolumn{9}{|c|}{$\begin{array}{l}\text { * UPDRS in off medication condition; † UPDRS in on medication condition; † Levodopa equivalent dose; §UPDRS in off medication, on stimulation condition } \\
\text { postoperatively }\end{array}$} \\
\hline & \multicolumn{7}{|c|}{ Table 2: Stimulation parameters of both the patients } & \\
\hline \multirow[t]{3}{*}{ Patient } & \multicolumn{8}{|c|}{ Stimulation parameters } \\
\hline & \multicolumn{4}{|c|}{ Channel 1 (Monopolar) } & \multicolumn{4}{|c|}{ Channel 2 (Monopolar) } \\
\hline & Active contact & Current & PW $\mu \mathrm{sec}$ & Freq. $\mathrm{Hz}$ & Active contact & Current & PW $\mu$ sec & Freq Hz. \\
\hline 1 & 2 & $1.9 \mathrm{~V}$ & 60 & 130 & 3 & $1.9 \mathrm{~V}$ & 60 & 130 \\
\hline 2 & 2 & $3.4 \mathrm{~V}$ & 60 & 185 & 2 & $3.3 \mathrm{~V}$ & 60 & 185 \\
\hline
\end{tabular}

\section{Patient 2}

A 58-year-old female suffering from advanced PD and drug-induced dyskinesias underwent STN stimulation surgery [Table 1]. She had no preoperative psychiatric problems and her MMSE examination was within normal limits. Postoperatively, there was remarkable improvement in her Parkinsonian symptoms and she gained $10 \mathrm{~kg}$ of weight. The postoperative LEDD was $700 \mathrm{mg}$, at the end of three months. Her stimulation parameters are mentioned in Table 2.

Postoperatively, her nurse said that she often forced herself into her husband's room to demand sex. In addition to this, losing all inhibitions, she also exposed herself to other males in the family and demanded sex. This was unlike her preoperative condition, where she had had no sexual relationship with her husband for several years except for an occasional instance where she forced herself into her husband's room. Postoperatively she became more vocal in expressing her sexual desires and frustration to the nurses looking after her. Also, though she had a liking for sweets, in spite of being diabetic, her craving increased postoperatively. Surprisingly, despite the evolution of these problems, whenever we evaluated her, she came across as an extremely mature person who showed no indications of her abnormal behavior. Even though there was significant clinical benefit, this aberrant behavior continued for a period of five years. This behavior was controlled with the introduction of Tab Clozapine, an antipsychotic drug.

\section{Discussion}

As the popularity of STN deep brain stimulation (DBS) increases, newer observations emerge, mainly related to behavioral and cognitive side-effects. ${ }^{[5,6]}$ Hypersexuality as a result of STN stimulation has been reported sparsely. ${ }^{[5,7]}$ Hypersexuality has also been reported as a side-effect of other PD surgeries such as pallidotomy, pallidal stimulation or subthalamic infarction. ${ }^{[9]}$ This is probably the first case report where manifestation of hypersexuality is a predominant behavioral side-effect of successful STN stimulation.

Both our patients witnessed significant improvement in their motor UPDRS and a drug reduction of $>50 \%$, ruling out the possibility of medications or inaccurate placement of electrodes as the cause of their symptoms.

Dopamine has an important role in the activity of medial preoptic anterior (MPOA) hypothalamic nuclei and stimulation of projections to the nucleus accumbens, both associated with sexual function. High-frequency STN stimulation has been shown to increase striatal dopamine in rat models, especially in the dopaminergic denervated model. ${ }^{[10]}$ It is known that motor effects produced by STN stimulation are similar to those produced by dopminergic treatment. ${ }^{[2]}$ It can be postulated that a similar mechanism works in human beings and the excess dopamine made available following STN DBS could result in hypersexuality. Another reason for this side-effect could be due to variable stimulation of the motor and limbic divisions of the $\mathrm{STN}^{[4]}$ or the current spread to surrounding structures.

Dopamine dysregulation syndrome (DDS) a syndrome characterized by compulsive and dysregulated drug use beyond the required levels to achieve relief of motor symptoms, is seen in $4 \%$ of patients suffering from PD. It is characterized by punding, hypersexuality, and pathological gambling or shopping. DDS is associated with a rapid and cyclic stimulation of the mesolimbic dopminergic pathways. STN DBS, through its constant stimulation, can also cause manic symptoms including hypersexuality ${ }^{[7]}$ in some patients. It is important to note that Patient 2 took to excessive eating, craving for sweets, etc. This may point towards the mechanism similar to DDS as an explanation for the hypersexuality.

One other explanation for hypersexuality is that the improvement in motor condition after stimulation therapy favored full expression of behavioral abnormalities. ${ }^{[6]}$ This may be the possible explanation in case of the female patient, but still does not explain 
the behavior of the older man.

In conclusion, we need to remember that along with motor benefits of STN stimulation, complex neuropsychological readjustments occur. It will be interesting to observe these changes as the treatment becomes more widely available.

\section{Acknowledgment}

I would like to express thanks to Mr. Parth Doshi for helping me with the editing of the manuscript.

\section{References}

1. Doshi PK, Chhaya NA, Bhatt MA. Bilateral subthalamic nucleus stimulation for Parkinson's disease. Neurol India 2003;51:43-8.

2. Krack P, Batir A, Van Blercom N, Chabardes S, Fraix V, Ardouin C, et $a l$. Five-year follow-up of bilateral subthalamic stimulation in advanced Parkinson's disease. N Engl J Med 2003;349:1925-34.

3. Doshi PK, Chhaya N, Bhatt MH. Depression leading to attempted suicide following bilateral subthalamic nucleus stimulation for Parkinson's disease. Mov Disord 2002;17:1084-5.

4. Bejjani BP, Damier P, Arnulf I, Thivard L, Bonnet AM, Dormont D, et al. Transient acute depression induced by high-frequency deep brain stimulation. N Engl J Med 1999;340:1476-80.
5. Temel Y, Kessels A, Tan S, Topdag A, Boon P, Visser-Vandewalle V. Behavioural changes after bilateral subthalamic stimulation in advanced Parkinson disease: A svstematic review. Parkinsonism Relat Disord 2006;12:265-72.

6. Houeto JL, Mesnage V, Mallet L, Pillon B, Gargiulo M, du Moncel ST, et al. Behavioral disorders, Parkinson's disease and sub-thalamic stimulation. J Neurol Neurosurg Psychiatry 2002;72:701-7

7. Romito LM, Raja M, Daniele A, Contarino MF, Bentivoglio AR, Barbier A, et al. Tansient Mania with Hypersexuality after surgery for high frequency stimulation of the subthalamic nucleus in Parkinson's disease. Mov Disord 2002;17:1371-4.

8. Castelli L, Perozzo P, Genesia ML, Torre E, Pesare M, Cinquepalmi $A$, et al. Sexual well being in Parkinsonian patients after deep brain stimulation of the subthalamic nucleus. J Neurol Neurosurg Psychiatry 2004;75:1260-4.

9. Absher JR, Vogt BA, Clark DG, Flowers DL, Gorman DG, Keyes JW, et al. Hypersexuality and hemiballism due to subthalamic infarction. Neuropsychiatry Neuropsychol Behav Neurol 2000;13:220-9

10. Lacombe E, Carcenac C, Boulet S, Feuerstein C, Bertrand A, Poupard A, et al. High-frequency stimulation of the subthalamic nucleus prolongs the increase in striatal dopamine induced by acute l-3,4-dihydroxyphenylalanine in dopaminergic denervated rats. Eur J Neurosei 2007;26:1670-80.

Accepted on 08-08-2008

Source of Support: Nil, Conflict of Interest: None declared. 